\title{
Mandibular angle fractures- intra oral and extra oral approaches - A comparative study
}

\author{
Abhinandan Patel K N $\mathbf{N}^{1}$, Girish $\mathbf{G}^{2 *}$, Sneha T $\mathbf{R}^{3}$ \\ ${ }^{\mathbf{1}}$ Associate Professor and HOD, ${ }^{2}$ Assistant Professor, ${ }^{3}$ Senior Resident, Dept. of Facio-maxillary Surgery, Sanjay Gandhi Institute of \\ Trauma and Orthopedics, Bengaluru, Karnataka, India \\ *Corresponding Author: Girish G \\ Email: drgirishggowda@gmail.com
}

\begin{abstract}
Aim: The aim of this study was to analyze outcomes of intra-oral and extra-oral approaches to mandibular angle fractures.

Materials and Methods: a retrospective study was performed of patients who underwent open reduction and internal fixation of mandibular angle fractures. Inpatient and outpatient records were reviewed for pertinent data including age, gender, presence of other fractures, surgical approach, operative time, and post-operative complications.

Results: The 40 patients with angle fracture, $60 \%$ were treated vis intra-oral approach and the rest $40 \%$ via extra-oral approach. The mean age of the patients were 30.87 years in the intra-oral group and 34.13 years in the extra-oral group. Main etiology of injury was RTA. The mean operating time for the intra-oral group was 95.63 minutes and 100.43 minutes for the extra-oral group. There was not much of difference in length of hospital stay for both the groups the mean being 2 days. Malocclusion was seen in $17.4 \%$ of extra-oral cases and $12.5 \%$ of intra-oral group. Re-surgery was performed in $12.5 \%$ of the extra-oral cases. Post-op infection was observed in $13 \%$ of intra-oral cases and $31.3 \%$ of extra-oral cases. Neurosensory disturbance occurred in $30 \%$ of extra-oral cases, and none in the intra-oral group, which is statistically significant. (p-0.017).

Conclusion- both methods of fixation for angle fractures are useful in the treatment. On the basis of our results we recommend using intraoral approach while clinically favorable with single miniplate along superior border.
\end{abstract}

Keywords: Mandbular angle fracture, Intraoral versus extra oral approach.

\section{Introduction}

Mandible is one of the most frequently fractured long bone of the face compared to other facial bones. ${ }^{1,2}$ The anatomy of the mandible makes mandibular angle region the most vulnerable, as ramus of the mandible makes an obtuse angle with body of the mandible. More over presence of impacted third molars and considerable amount of space occupied by the same makes the angle a lever of the mandible., ${ }^{3,4}$ The cross section area of the mandible angle is thinner than the body and ramus. ${ }^{5}$ In the last two decades interest has increased for different methods of ORIF. ${ }^{6}$ As fixation devices got modified in their size and shape with more convenience to handle, extra oral incisions have been minimized.However, optimal treatment remains unconcluded. ${ }^{7,8}$ Numerous studies conducted fails to testify a single approach for angle fracture. ${ }^{9}$ Extra oral approaches has a potential disadvantage of facial nerve injury, scar etc, however better exposure and ease of implant application makes it more advantageous. ${ }^{10,11}$ Champy et.al, and other authors documented low complication rate with monocortical plate fixation for intraoral open reduction as the single miniplate placed vertical to oblique line of buccal cortex. $^{12,13}$ The advantages are, no external scaring, no injury to nerve, and also allow confirmation of occlusion during plate placement and direct visualization of the fracture site. However intra oral approach have some doubt in the degree of stability provided by the intra oral miniplate. ${ }^{14}$ There is always a risk of infection from the contamination of the oral cavity, ease of access and presence of impacted $3^{\text {rd }}$ molars. In our study, the ease of approach to the site in relation to time taken for the surgery, visualization of fracture site, ease of fracture reduction and post-operative complications involved were compared for intra oral and extra oral approaches.

\section{Materials and Methods}

A retrospective study was conducted of the inpatient and outpatient medical records of patients with mandibular angle fractures at the department of facio-maxillary surgery, Sanjay Gandhi institute of trauma and orthopedics.The inclusion criteria were: patients with angle fracture that required open reduction and internal fixation, age between 18-60 years irrespective of gender,

The exclusion criteria was- patients with pre-existing medical conditions, infected fracture site, patients who were treated by closed reduction.

Charts of patients were reviewed for age, gender, presence of other fractures, type of surgical approach, number of plates, OT time, which was calculated fromthe beginning of the incision till the closure. Length of admission and complications such as malocclusion, nonunion, re-operation, post-op infection, neurosensory deficit, facial nerve injury, implant retrieval, scarring and wound dehiscence.

Intraorally the fixation was done with four hole centrally spaced $2 \mathrm{~mm}$ miniplate placed anteriorly on the external oblique ridge. For extra oral approach skin incision was given in the submandibular region followed by layered dissection and fixation of fracture with one miniplate.

Preop and postop radiographs were taken and the patients were followed up for 3 months. 
Table 1: Demographics of study population

\begin{tabular}{|l|c|c|}
\hline & $\begin{array}{c}\text { Intra- oral } \\
\text { approach } \\
(\mathbf{n = 2 3 )}\end{array}$ & $\begin{array}{c}\text { Extra- oral } \\
\text { approach } \\
(\mathbf{n = 1 7 )}\end{array}$ \\
\hline Age (mean, [SD]) & 11.918 & 12.420 \\
\hline Sex (\% male) & 100 & 93.8 \\
\hline $\begin{array}{l}\text { Other mandibular } \\
\text { fractures (\% present) }\end{array}$ & 52.1 & 68.9 \\
\hline
\end{tabular}

\section{Results}

There were a total of 40 patients with mandibular angle fracture who underwent open reduction and internal fixation, $23(60 \%)$ of them were treated intra-orally and the remaining $17(40 \%)$ of them extra orally. Male patients formed the majority of mandibular angle fractures (93.8\%) in extra-oral group and $100 \%$ in intra-oral approaches $(\mathrm{p}=0.85)$. the mean age of patients in intra-oral group was 30.87 years and 34.13 years in the other group with a standard deviation of 11.918 and 12.42 respectively. The main etiology of injury was RTA in both the groups. $4.3 \%$ of cases in intra-oral group and $12.5 \%$ in the extra-oral group were bilateral angle fractures with a $\mathrm{P}$ value of 0.90 . Of the cases approached intra-orally, 52\% had multiple fractures, whereas $68.9 \%$ of the extra-oral cases were associated with other fractures (P value- 0.87 ). The mean operating room time for intra-oral approach was 95.63 minutes when compared to 100.43 minutes for extra-oral approach with a $\mathrm{p}$ value of 0.54 .Further Mann-Whitney test was applied for the operating room time for which a score of 163 was obtained. There was not much of difference in the length of hospital stay between the 2 groups. Intra-oral approach had a mean length of stay of 2.74 days and 2.81 days for extra-oral approach with a $\mathrm{p}$ value of 0.77 and a standard deviation of 0.75 . Malocclusion was seen in $17.4 \%$ of extra-oral cases and $12.5 \%$ of intra-oral approach patients, with a $p$ value of 0.97 . Non union was not seen in any of the cases. Re-surgery was performed in $12.5 \%$ of the extra-oral cases and none in the intra-oral group. ( $p$ value0.31 ). Post-op infection was observed in $13 \%$ of intra-oral cases and $31.3 \%$ of extra-oral cases with a $\mathrm{p}$ value of 0.32 . Neurosensory disturbance occurred in $30 \%$ of extra-oral cases ( $p$ value - 0.35 ) out of the 11 cases of extra-oral approach 5 cases experienced facial nerve injury and none in the intra-oral group, $\mathrm{p}$ vale of 0.017 which is found to be significant. In the entire sample $31.3 \%$ of cases experienced facial nerve injury.

Table 2: Complications following intraoral and extraoral procedures

\begin{tabular}{|c|c|c|c|c|c|c|c|}
\hline 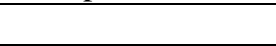 & & \multicolumn{2}{|c|}{ Extra oral } & \multicolumn{2}{|c|}{ Intra oral } & \multirow[b]{2}{*}{$P$ value } & \multirow[b]{2}{*}{ Chi-square value } \\
\hline Variable & Level & $\mathbf{N}$ & $\%$ & $\mathbf{N}$ & $\%$ & & \\
\hline \multirow{2}{*}{ Malocclusion } & Yes & 2 & 12.5 & 4 & 17.4 & \multirow[t]{2}{*}{0.97} & \multirow[t]{2}{*}{0.001} \\
\hline & No & 15 & 87.5 & 19 & 82.6 & & \\
\hline \multirow[t]{2}{*}{ Non-union } & Yes & 0 & 0 & 0 & 0 & \multirow[t]{2}{*}{ - } & \multirow[t]{2}{*}{ - } \\
\hline & No & 17 & 100 & 23 & 100 & & \\
\hline \multirow[t]{2}{*}{ Re-operation } & Yes & 2 & 12.5 & 0 & 0 & \multirow[t]{2}{*}{0.31} & \multirow[t]{2}{*}{1.006} \\
\hline & No & 15 & 87.5 & 23 & 100 & & \\
\hline \multirow[t]{2}{*}{ Post-op infection } & Yes & 5 & 31.3 & 3 & 13.0 & \multirow[t]{2}{*}{0.32} & \multirow[t]{2}{*}{0.96} \\
\hline & No & 12 & 68.8 & 20 & 87.0 & & \\
\hline \multirow{2}{*}{$\begin{array}{l}\text { Neurosensory } \\
\text { deficit }\end{array}$} & Yes & 2 & 12.5 & 7 & 30.4 & \multirow[t]{2}{*}{0.35} & \multirow[t]{2}{*}{0.84} \\
\hline & No & 15 & 87.5 & 16 & 69.6 & & \\
\hline \multirow[t]{2}{*}{ Facial nerve injury } & Yes & 5 & 31.3 & 0 & 0 & \multirow[t]{2}{*}{$0.017 *$} & \multirow[t]{2}{*}{5.68} \\
\hline & No & 12 & 68.8 & 23 & 100 & & \\
\hline \multirow[t]{2}{*}{ Wound dehiscence } & Yes & 4 & 25 & 3 & 13.0 & \multirow[t]{2}{*}{0.59} & \multirow[t]{2}{*}{0.28} \\
\hline & No & 13 & 75 & 20 & 87.0 & & \\
\hline \multirow[t]{2}{*}{ Implant retrieval } & Yes & 2 & 12.5 & 0 & 0 & \multirow[t]{2}{*}{0.35} & \multirow[t]{2}{*}{0.84} \\
\hline & No & 15 & 87.5 & 23 & 100 & & \\
\hline \multirow[t]{2}{*}{ Extra-oral scarring } & Yes & 5 & 31.3 & 0 & 0 & \multirow[t]{2}{*}{$0.017 *$} & \multirow[t]{2}{*}{5.68} \\
\hline & No & 12 & 68.8 & 23 & 100 & & \\
\hline
\end{tabular}




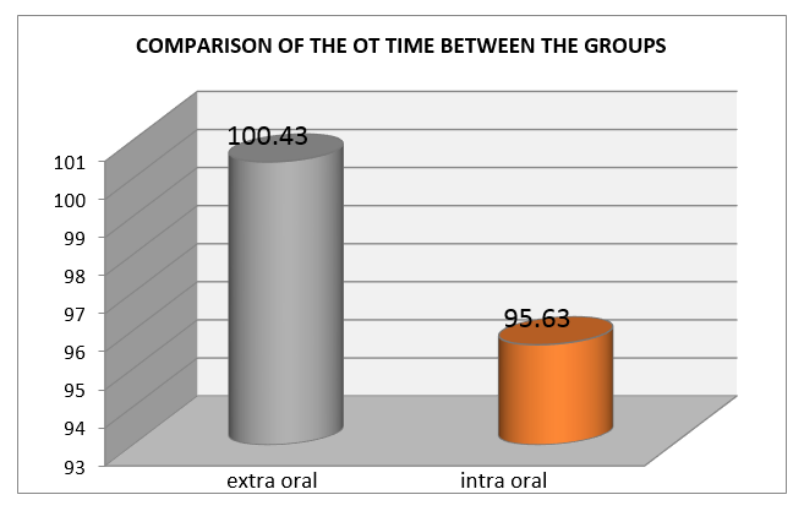

Fig. 1

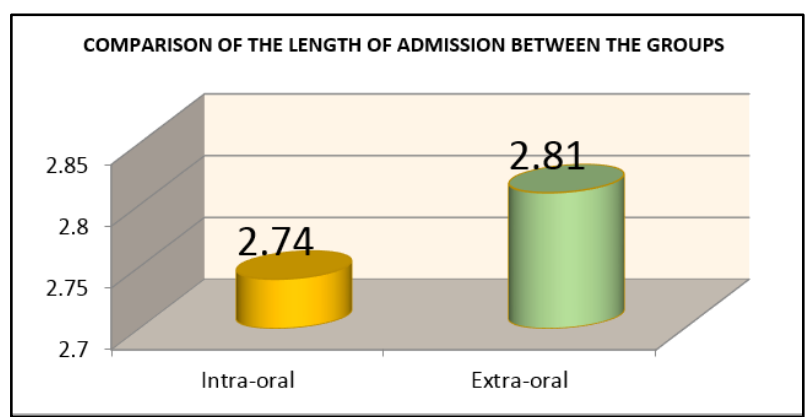

Fig. 2

\section{Discussion}

The ideal approach for the treatment of mandibular angle fractures continues to be a topic of research and debate. ${ }^{15} \mathrm{We}$ intended to compare the introral and extraoral approaches for the treatment of angle fractures in terms of outcomes. Male patients formed the majority in our study as appeared in other studies. In our study it was observed that average age of the patients in extra oral group were 4 years older than the intra oral group. Although this age difference is not clinically significant, it may point to the fact that patients age may change the surgeons decision for approach. As it reflects the surgeons desire to avoid extra oral scaring in younger individuals or a supposition for better healing in younger individuals. ${ }^{16}$ Presence of additional mandibular fractures was moderately associated with an extraoral approach to repair. This may mean that more complicated mandibular fractures were approached extraorally. Rate of complications in this study were comparable or slightly higher, especially with the extraoral approach, than those present in other studies. This may be due to the small sample size considered for the study. The most common complication with mandibular fractures is infection, especially angle region. Intra oral infection rate was $13 \%$ versus $31.3 \%$ for the extra oral group as compared with the other studies ranging from $1.5 \%$ to $28 \% .{ }^{17}$ increased extra oral infection rate could be attributed to increased OT time and improper patient maintenance and wound dehiscence as seen in our study. Plate retrieval was higher in the extra oral group than the intra oral group $(12.5 \% \mathrm{v} / \mathrm{s} 0.0 \%)$. This need for plate removal was attributed to infection and wound dehiscence. ${ }^{19}$ Neurosensory disturbance was seen in $30.4 \%$ of intraoral group when compared to $12.5 \%$ of extraoral group. A rate ranging from $3.3 \%-20 \%$ is reported in the literature. ${ }^{16,18}$ in $31.3 \%$ of extra oral cases unfavorablescarring was reported, as compared with reports ranging from $3.3 \%$ to $6.15 \% .^{16,18} 12.5 \%$ of the extraoral cases experienced transient malocclusion when compared to $17.4 \%$ of intraoral cases. This may implicate towards the difficulty experienced during anatomic reduction of the fracture as well as accessibility to the surgical site when approached intraorally. A range of $3.3 \%-8.3 \%$ is reported in the literature. ${ }^{18}$ both the methods of fixation are comparably successful for the treatment of mandibular angle fractures. A slightly higher rate of complications was seen for postop infection, facial nerve injury, wound dehiscence, implant retrieval and unfavorable scar in cases approached extraorally. A weighted statistical analysis revealed clinically significant increased complication rate for extra oral group for facial nerve injury and unfavorable scaring. $(p=0.017)$ operating room time was significantly lower for intra oral group, a mean of $95.63 \%$ minuteswhen compared to 100.43 minutes for extra oral approach, Which is in contrast to Toma et al., who's study showed an additional 20 minutes of operating time for intra oral approach. Length of hospital stay was slightly higher in the extra oral group compared to the intra oral groups. One of the limitations of our study is that it is a retrospective review, it is not possible to compare intra oral versus extra oral approaches without randomization. Why a surgeon chooses a specific method of approach to the angle fracture cannot be reasoned out precisely. Some of the determining factors are the age of the patient, severity of the fracture, patient preference and finally the comfort and training of the surgeon. However it is confirmed by other studies, including Ellis that he intra oral technique of angle fracture treatment with single miniplate along the superior border is associated with fewest complications. Future prospective studies of angle fracture repair will provide more clarity on the most appropriate approach for angle fracture treatment. A 7 year long retrospective analysis done by Mehra and Murat on isolated angle fracture, treated with a single monocortical plate intraoraly and inferior border platting extraorally, showed similar results as our study. They recommended intra oral approach for the fixation of mandibular angle fractures. ${ }^{16}$ Our study differs by encompassing, patients with multiple fractures and analysis of length of hospital stay.

\section{Conclusion}

Both the methods of fixation are useful in the treatment of angle fractures of the mandible. On the basis of our results we recommend to use intraoral approach while clinically favorable with single miniplate along the superior border. This is attributed to successful repair and shorter recovery time.

\section{Source of funding}

None.

\section{Conflict of interest}

None. 


\section{References}

1. Kuriakose MA, Fardy M, Sirikumara M, Patton DW, Sugar AW. A comparative review of 266 mandibular fractures with internal fixation using rigid (AO/ASIF) plates or mini-plates. Br J Oral Maxillofac Surg 1996;34:315-21.

2. Rix L, Stevenson AR, Punnia-Moorthy A. An analysis of 80 cases of mandibular fractures treated with miniplate osteosynthesis. Int J Oral Maxillofac Surg 1991;20:337-41.

3. Fonseca RJ, Walter RV. Oral and Maxillofacial Trauma. 2nd ed.,Vol. 1. Pennsylvania: W.B. Saunders Company; 1997. p. 474-8.

4. Leonard PF. Fractures: A History and Iconography of their Treatment. No. 3. Novata CA Norman Publishing; 1990.

5. Schubert W, Kobienia BJ, Pollock RA. Cross-sectional area of the mandible. J Oral Maxillofac Surg 1997;55689-692-3.

6. Ellis E 3rd. Treatment methods for fractures of the mandibular angle. Int J Oral Maxillofac Surg 1999;28:243-52.

7. Gear AJ, Apasova E, Schmitz JP, Schubert W. Treatment modalities for mandibular angle fractures. J Oral Maxillofac Surg 2005;63(5):655-63. http://dx.doi.org/10.1016/j.joms.2004.02.016 PMid:15883941

8. Zix J, Lieger O, Iizuka T. Use of straight and curved 3dimensional titanium miniplates for fracture fixation at the mandibular angle. J Oral Maxillofac Surg 2007;65(9):1758-63. http://dx.doi.org/10.1016/j.joms.2007.03.013 PMid:17719394

9. Guimond C, Johnson JV, Marchena JM. Fixation of mandibular angle fractures with a 2.0-mm 3- dimensional curved angle strut plate. J Oral Maxillofac Surg 2005;63(2):209-14. http://dx.doi.org/10.1016/j.joms.2004.03.018 PMid:15690289

10. Toma VS, Mathog RH, Toma RS, Meleca RJ. Transoral versus extra-oral reduction of mandible fractures: A comparison of complication rates and other factors. Otolaryngol Head Neck Surg 2003;128(2):215-9. http://dx.doi.org/10.1067/mhn.2003.59 PMid:12601317

11. Pattar P, Shetty S, Degala S. A Prospective Study on Management of Mandibular Angle Fracture. J Maxillofac Oral
Surg 2014;13(4):592-8. http://dx.doi.org/10.1007/s12663-0130542-3 PMid:26225033 PMCid:PMC4518788

12. Champy M, Lodde JH, Must D. Mandibular osteosynthesis with miniaturized screwed plates via buccal approach. $\underline{J}$ Maxillofac Surg 1978;6:14.

13. Michelet FX, Deynos I, Dessus B. Osteosynthesis with miniaturized screwed plate in Maxillofacial Surgery. $J$ Maxillofac Surg 1973;1:79.

14. Choi BH, Kim KN, Kang HS. Clinical \& in vitro evaluation of mandibular angle fracture fixation with two miniplate system. Oral Surg 1995;79:692.

15. Hsueh WD, Schechter CB, Tien Shaw I, Stupak HD. Comparison of intraoral and extraoral approaches to mandibular angle fracture repair with cost implications. The Laryngoscope 2016;126(3):591-5.

16. Mehra P, Murad H. Internal fixation of mandibular angle fractures: a com- parison of 2 techniques. J Oral Maxillofac Surg 2008;66:2254-60.

17. Potter J, Ellis E 3rd. Treatment of mandibular angle fractures with a mal- leable noncompression miniplate. J Oral Maxillofac Surg 1999;57:288-92.

18. Moreno JC, Fernandez A, Ortiz JA, Montalvo JJ. Complication rates associated with different treatments for mandibular fractures. J Oral Maxillofac Surg 2000;58:273-80.

19. Pattar P, Shetty S, Degala S. A Prospective Study on Management of Mandibular Angle Fracture. J Maxillofac Oral Surg 2014;13(4):592-8.

How to cite this article: Patel AKN, Girish G, Sneha TR. Mandibular angle fractures- intra oral and extra oral approaches - A comparative study. J Oral Med, Oral Surg, Oral Pathol, Oral Radiol 2019;5(3):68-71. 